Jan Steininger - Stefan Medvecky - Robert Kohar - Tomas Capak

\title{
OPTIMIZATION PROCEDURE OF ROLLER ELEMENTS GEOMETRY WITH REGARD TO DURABILITY OF SPHERICAL ROLLER BEARINGS
}

The article deals with an optimization procedure of roller elements geometry with regard to durability of spherical roller bearings. The aim of the article is to examine the impact of change of the roller elements inner geometry on durability and reliability of spherical roller bearings; the contact strain along a spherical roller by means of the Finite Element Method at contact points of components of a spherical roller bearing by means of designed $3 D$ parametric models. The most appropriate shape of roller elements inner geometry of a bearing from the standpoint of calculated durability was determined based on results of the contact analyses.

Keywords: rolling element, contact strain, spherical roller bearing

\section{Introduction}

Roller bearings are an inseparable part of most machines and devices in which there takes place a rotation movement or a linear motion. There are different requirements on roller bearings. Production machines need bearings, which are able to work in high revolution, in power engineering bearings have to carry heavy loads, etc.

Development, or rather rolling bearing optimization, is conditioned by an increase of technical parameters in machines and devices. This fact refers especially to an increase of input parameters such as power and revolution, weight and volume reduction, noise level reduction, etc. However, the most important parameters requiring optimization are the bearing lifetime and reliability.

Development of new technologies introduces also new construction materials, new production techniques of semi-finished products and bearing components or new installation methods. It is important not to overlook the bearing construction. Here it is possible to perform geometry adjustment optimization. This adjustment applies especially to geometry adjustment of raceways and rolling elements in the spherical roller bearings.

\section{Spherical roller bearings durability}

The double-row angular spherical roller bearing has a raceway spherically ground on the outer ring. The bearing is able to accommodate very high radial loads, as well as heavy axial loads in both directions. The high radial load capacity is caused by the great number of rolling elements, the so-called spherical rollers and their close contact on the inner ring raceways [1].
Roller bearings durability depends on a revolution number, which the bearing can perform until fatigue of any of their components takes place. A peeled material is a sign of the component fatigue. Fatigue is a basic and natural way of bearing damage. It is demonstrated by the presence of small cracks under the bearing raceway surface. The depth of these cracks is usually about $0.05-0.3 \mathrm{~mm}$ depending on the surface curve radii of rolling elements and the bearing ringsraceways. The crack depth allows the material changes, which are caused by the slide pulsating strain. This process leads to a gradual crack formation under the surface. It can take quite a long time until it is visible on the surface in a form of the peeled off material, the so-called pitting [2-3]

\section{Contact strain along spherical roller} in a spherical roller bearing

It is possible to calculate the intensity of the contact pressure and the size of the contact surface - effective length $\mathrm{l}_{\text {ef }}$ and width $2 \mathrm{~b}$ from the contact pressure distribution at the most strained point in the bearing inner ring. Figure 1 shows the course projection (the curve) of the contact pressure along the contact surface $l_{\text {ef }}$ of the contact ellipse on the bearing inner ring. The contact strain curve has been calculated using the finite element method [4].

\section{Optimization of geometry of spherical roller bearing}

The bearing model was simplified by axial symmetry. the bonds between the individual parts of the bearing were

\footnotetext{
Jan Steininger ${ }^{1}$, Stefan Medvecky ${ }^{1}$, Robert Kohar ${ }^{2, *}$, Tomas Capak ${ }^{2}$

${ }^{1}$ Institute of Competitiveness and Innovations, University of Zilina, Slovak Republic

${ }^{2}$ Department of Design and Mechanical Elements, Faculty of Mechanical Engineering, University of Zilina, Slovak Republic

*E-mail of corresponding author: robert.kohar@fstroj.uniza.sk
} 


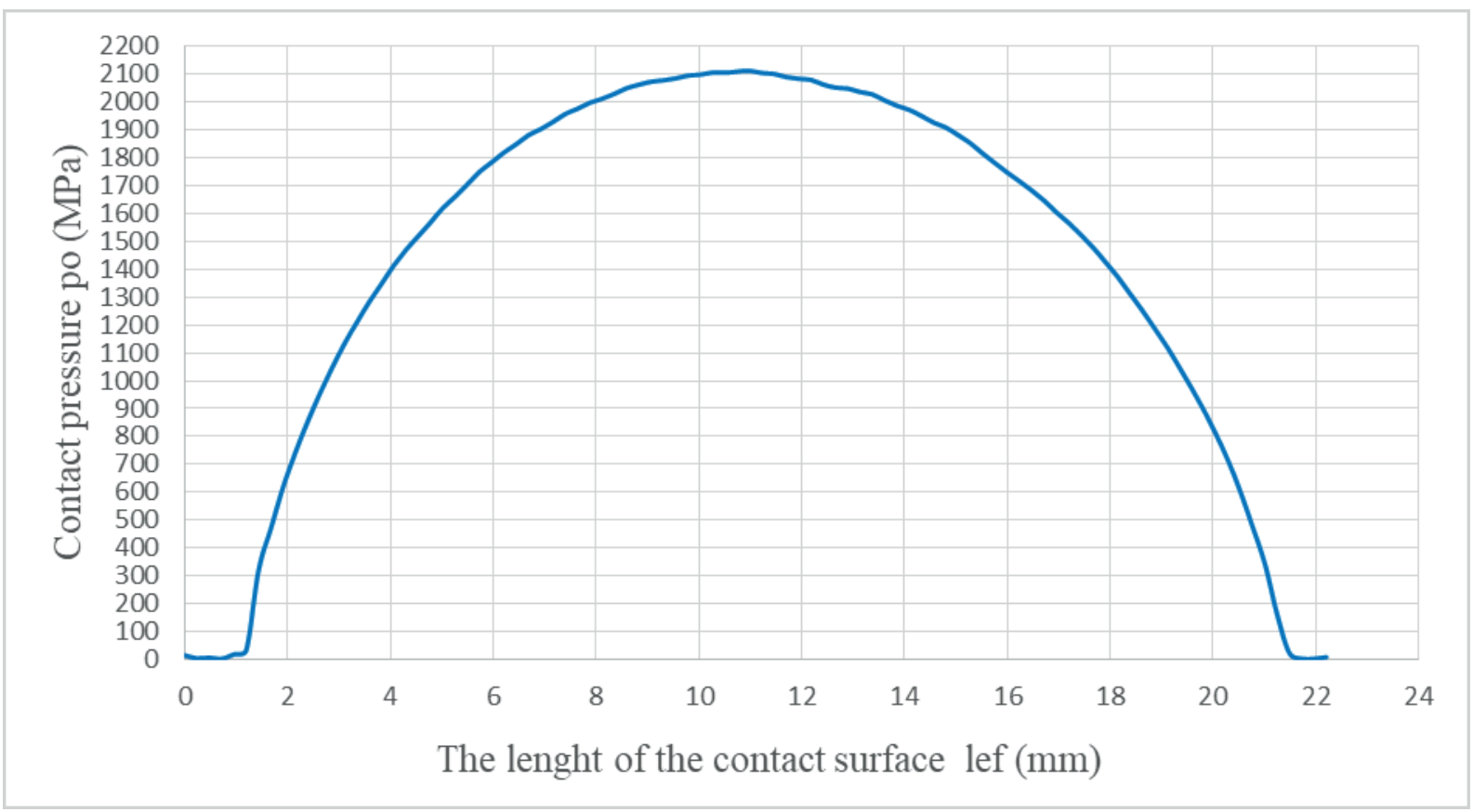

Figure 1 The contact pressure course on the inner bearing ring raceway

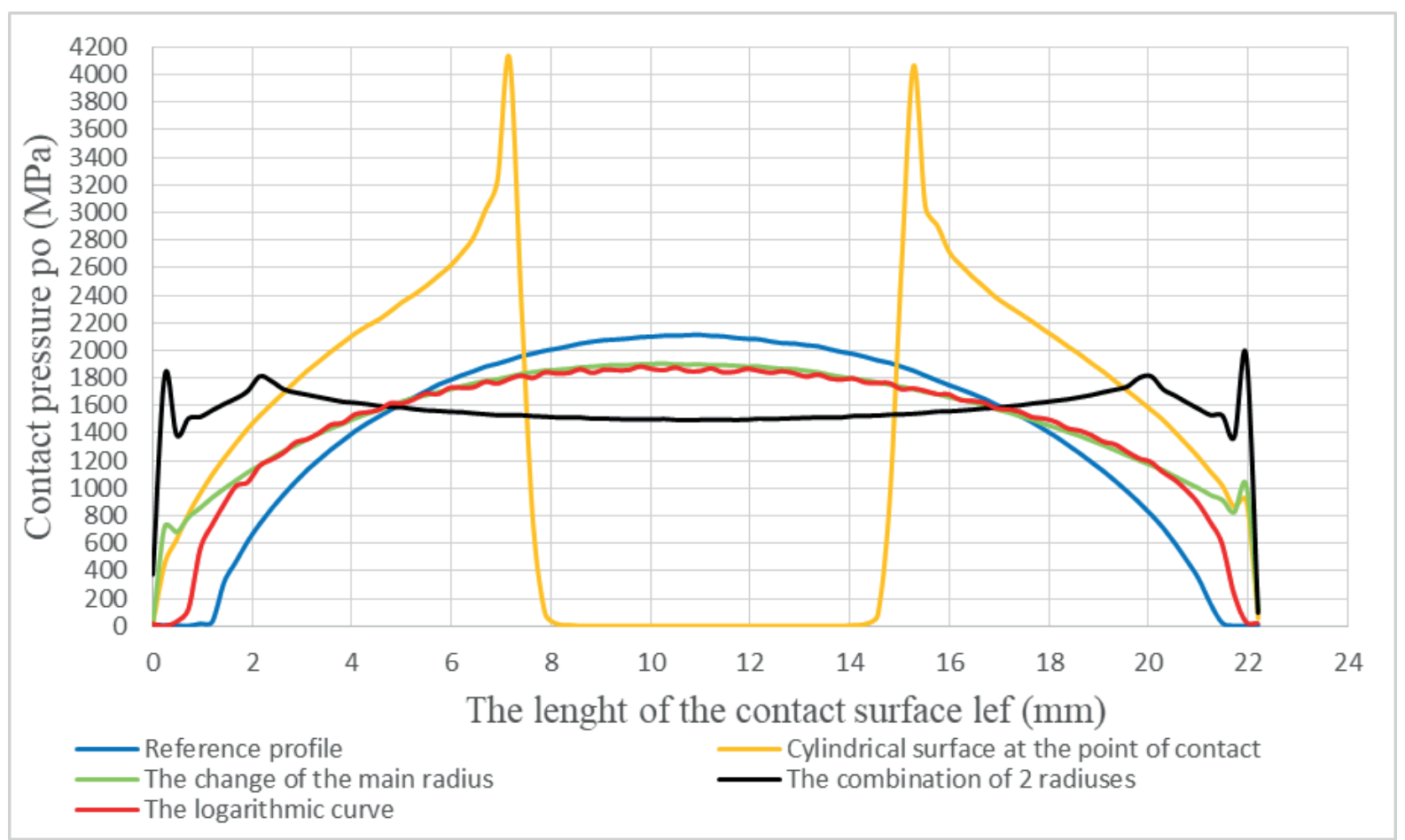

Figure 2 Comparison of the contact pressure courses in the bearing raceway of the spherical roller bearing inner ring for the rolling element analyzed geometries

replaced by contacts. Degrees of freedom were taken from the outer ring of the bearing. The rolling element load calculation is based on the Hertz theory and the reference bearing calculation data. It is possible to distribute the bearing load to individual rolling elements. The load on the selected part of the bearing was calculated to be $9 \mathrm{kN}$. The contact volumes were meshed with $0.08 \mathrm{~mm}$ hexahedrons. The other parts were meshed with $0.56 \mathrm{~mm}$ tetrahedrons. The transition edges were meshed at $0.24 \mathrm{~mm}[5-6]$.
The aim of optimization was a decrease of contact pressure that acts at the point of contact of the rolling element with the outer and the inner ring. The profile of a rolling element was optimized and the contact strain between the rolling elements and bearing rings was calculated, as well [7].

The three new geometries of the rolling element for spherical roller bearings were designed that were consequently compared with the reference profile. Selection of the most appropriate design of the new geometry of the 


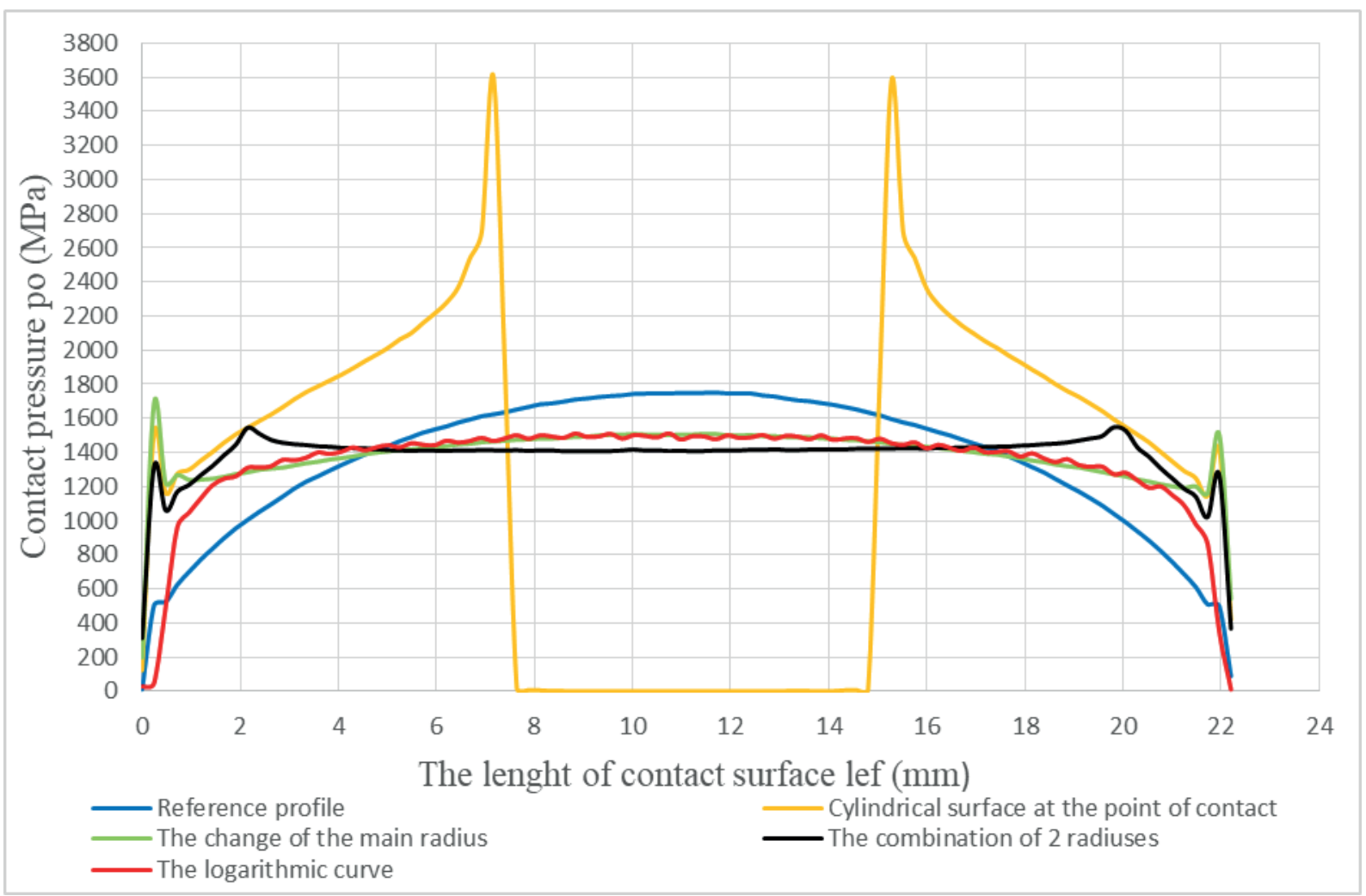

Figure 3 Comparison of the contact pressure courses in the bearing raceway of the spherical roller bearing outer ring for the rolling element analyzed geometries

Table 1 Evaluation of results of analyses in the spherical roller bearing inner ring

\begin{tabular}{|c|c|c|c|c|c|}
\hline Design nr. & Title & $\mathrm{l}_{\mathrm{ef}}(\mathrm{mm})$ & $\mathrm{b}_{\mathrm{ef}}(\mathrm{mm})$ & $\mathrm{p}_{\mathrm{o}}(\mathrm{MPa})$ & $\sigma_{\max }(\mathrm{MPa})$ \\
\hline $\begin{array}{l}\text { Reference } \\
\text { bearing }\end{array}$ & Profile & 21 & 0.96 & 2106.1 & 1426 \\
\hline 1 & $\begin{array}{c}\text { Cylindrical surface at the point } \\
\text { of contact }\end{array}$ & 22.14 & 1.21 & 4022.1 & 3019.1 \\
\hline 2 & The change of the main radius & 22.13 & 0.96 & 1921.5 & 1319.9 \\
\hline 3 & The combination of 2 radii & 22.14 & 0.64 & 2106.1 & 1315.3 \\
\hline 4 & Logarithmic curve & 21.9 & 0.63 & 1948.3 & 1302.6 \\
\hline
\end{tabular}

Table 2 Evaluation of results of analyses in the spherical roller bearing outer ring

\begin{tabular}{cccccc}
\hline Design nr. & Title & $\mathrm{l}_{\mathrm{ef}}(\mathrm{mm})$ & $\mathrm{b}_{\mathrm{ef}}(\mathrm{mm})$ & $\mathrm{p}_{\mathrm{o}}(\mathrm{MPa})$ & $\sigma_{\max }(\mathrm{MPa})$ \\
\hline $\begin{array}{c}\text { Reference } \\
\text { bearing }\end{array}$ & Profile & 21.8 & 0.8 & 1758.4 & 1426 \\
1 & $\begin{array}{c}\text { Cylindrical surface at the point } \\
\text { of contact }\end{array}$ & 22.13 & 0.99 & 3658.6 & 3019 \\
2 & The change of the main radius & 22.14 & 1.21 & 2048.7 & 1319.9 \\
3 & The combination of 2 radii & 22.14 & 1.18 & 1719.7 & 1315.3 \\
4 & Logarithmic curve & 22 & 0.64 & 1576.9 & 1302.6 \\
\hline
\end{tabular}

rolling element was based on comparison of the contact pressures on bearing raceways of the inner and outer bearing rings.

The comparison of curves of the rolling elements contact pressures depends on the length of the contact surface $l_{\text {ef }}$ Figure 2 (inner ring) and Figure 3 (outer ring) show the curves' shape. A decrease of contact pressure on bearing raceways of bearing rings was obtained in all the designs of a new geometry of the rolling element [7-8].

As shown in Figures 2 and 3, the lowest contact pressure acts between the two bearing rings and the rolling element with new geometry 4 . At the same time, the contact pressure that acts between the bearing rings and the rolling element does not produce maximum strain 


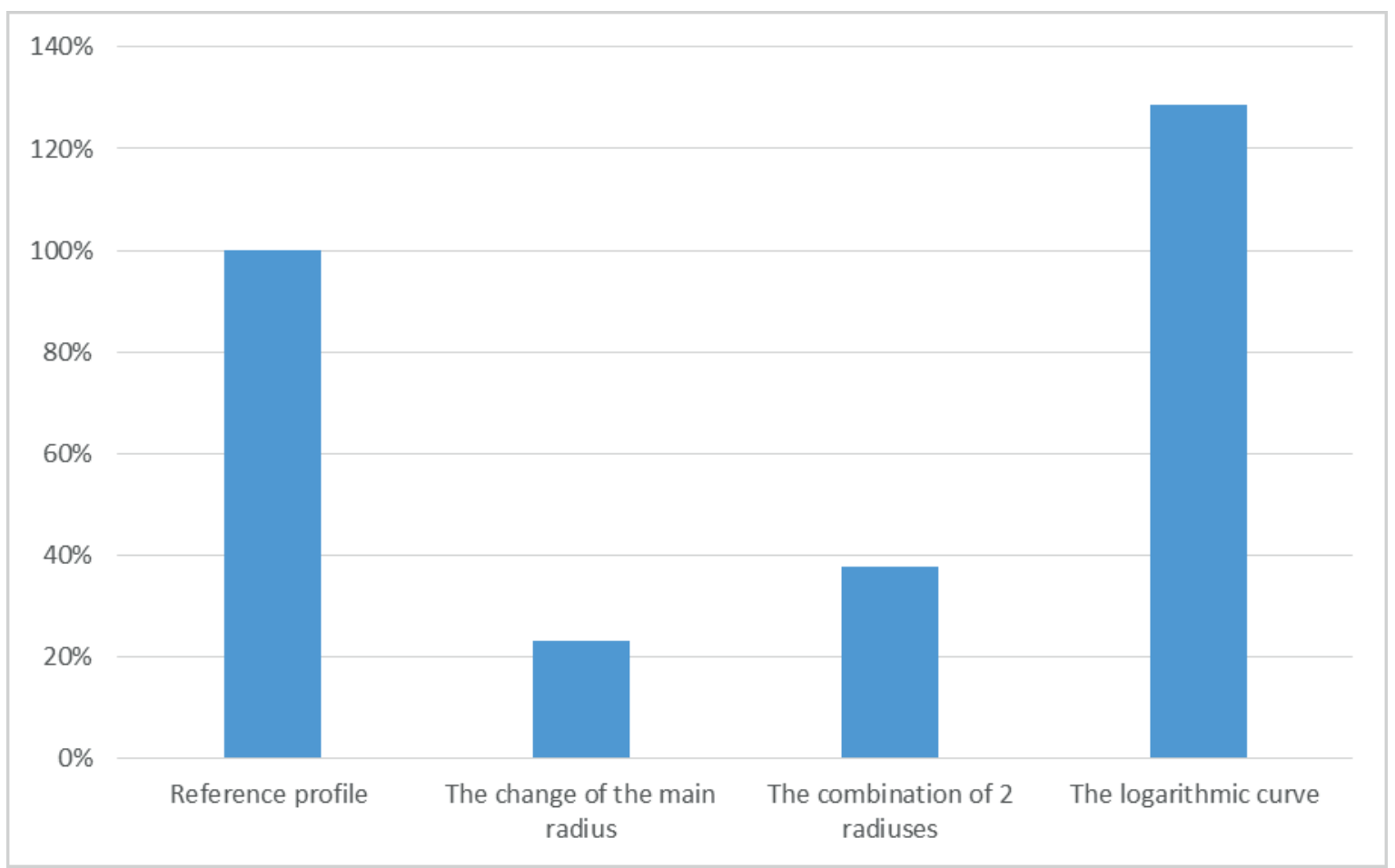

Figure 4 Comparison of calculated lifetimes of analysed geometries

values that negatively affect the bearing durability. The new geometry of the spherical roller bearing formed by the logarithmic curve is the most appropriate for optimization of the spherical roller bearing regarding its durability and lifespan [8].

Evaluation and selection of the most appropriate design of the new geometry are shown in Table 1 and Table 2 , respectively.

For the better evaluation of analysed geometries durability of individual analysed geometries was calculated according to the Lundberg-Palmgren theory:

$\ln \frac{1}{s} \approx A * \frac{N^{e} * \tau_{0}^{c} * V}{z_{0}^{h}}$,

$\tau_{0} \approx 0.256 * p_{0}$,

$z_{0} \approx 0.25 * 2 b$,

where: $S$ is the probability of survival,

$N$ is the number of load cycles,

$V$ is the stressed volume,

$e, c, h, A$ are material constants defined by experiments,

$p_{0}$ is the pressure present at the contact point,

$2 b$ is the minor axis of the ellipse [9].

Calculation of a total lifetime of the bearing was based on partial lifetimes of bearing rings. As far as a logical comparison is concerned, $100 \%$ is assigned to the reference geometry.

In a new design 1 (Cylindrical surface at the point of contact), the calculated pressures are well above those of the reference bearing. Therefore, the analysis of the new design 1 is excluded from further comparison.
Comparison of the calculated lifetimes of analysed geometries is shown in Figure 4 [10].

\section{Conclusions}

Spherical roller bearings can be optimized by modification of the geometry of the rolling element, i.e., the spherical roller. The most appropriate geometry seems to be the one formed by the logarithmic curve after a comparison of lifetimes of the bearing with the new geometry of the rolling element (Figure 4). The logarithmic curve is described by equations, while in this case a parameter of a loss of the logarithmic curve profile, i.e., a modified surface of the spherical roller. The optimal value of the parameter is $0.00035 \mathrm{~mm}$ which is similar as in the case of the rolling bearing with the logarithmic profile.

The new geometry of the rolling bearing composed by the logarithmic curve increases the total carrying capacity and thus bearing durability by more than $25 \%$. This new geometry does not form the strain peaks that negatively affect the total bearing durability.

\section{Acknowledgment}

This work was supported by the Grant system of the University of Zilina and by Ministry of Education, Science, Research and Sport under the contract No. 1/0595/18 Optimising the internal geometry of roller bearings with line contact in order to increase their durability and reduce their structural weight. 


\section{References}

[1] LUNDBERG, G., PALMGREN, A. Dynamic capacity of rolling bearings. Acta Polytechnica Scandinavica, Mechanical Engineering Series. 1952, 2(4), p. 96. ISSN 0001-687X.

[2] STASTNIAK, P., MORAVCIK, M, BARAN, P., SMETANKA, L. Computer aided structural analysis of newly developed railway bogie fram. In: 21st Polish-Slovak Scientific Confeerence on Machine Modelling and Simulations 2017: proceedings. 2017. ISSN 2261-236X, p. 1-10.

[3] SKYBA, R., HRCEK, S., SMETANKA, L., MAJCHRAK, M. Stiffness analysis of slewing bearings. In: 10th International Conference Machine and Industrial Design in Mechanical Engineering: proceedings. Bristol: IOP Publishing, 2018. ISSN 1757-8981, eISSN 1757-899X, ISBN 9781510868649, p.1-7.

[4] BELORIT, M., HRCEK, S., SMETANKA, L. Mathematical algorithm for calculating an optimal axial preload of rolling bearings with the respect to their life. In: 10th International Conference Machine and Industrial Design in Mechanical Engineering : proceedings. Bristol: IOP Publishing, 2018. ISSN 1757-8981, eISSN 1757-899X, ISBN 9781510868649, p 1-10.

[5] SKYBA, R., HRCEK, S., SMETANKA, L., MAJCHRAK, M. Strength analysis of slewing bearings. In: TRANSCOM 2019: proceedings. 1. ed. Amsterdam: Elsevier Science, 2019. ISSN 2352-1465, p. 891-897.

[6] MRUZEK, M., GAJDAC, I., KUCERA, L., BARTA, D. Analysis of parameters influencing electric vehicle range. Procedia Engineering [online]. 2016, 134, p. 165-174. ISSN 1877-7058. Available from: https://doi.org/10.1016/j.proeng.2016.01.056

[7] GUO, Y., PARKER, R. Stiffness matrix calculation of rolling element bearings using a finite element/contact mechanics model. Mechanism and Machine Theory [online]. 2012, 51, p. 32-45. ISSN 0094-114X, eISSN 1873-3999. Available from: https://doi.org/10.1016/j.mechmachtheory.2011.12.006

[8] FATURIK, L., TRSKO, L., HRCEK, S., BOKUVKA, O. Comparison of structural design in high and ultra-high cycle fatigue regions. Transactions of FAMENA [online]. 2014, 38(4), p. 1-12. ISSN 1333-1124, eISSN 1849-1391. Available from: https://hrcak.srce.hr/135872

[9] STASTNIAK, P., MORAVCIK, M, SMETANKA, L. Investigation of strength conditions of the new wagon prototype type Zans. In: 23th Polish-Slovak Scientific Confeerence on Machine Modelling and Simulations: proceedings. 2019. ISSN 2261-236X, p. 1-11.

[10] HARRIS, A. Advanced concepts of bearing technology. USA: CRC Press Taylor and Francis Group, 2006. ISBN 10 0-8493-7182-1. 